\title{
PRECIPITAÇÃo MENSAL E ANUAL PROVÁVEL NO ESTADO DE SANTA CATARINA
}

\author{
COAN, Bruno De Pellegrin - brunocoan@gmail.com \\ Universidade do Extremo Sul Catarinense \\ BACK, Álvaro José - ajb@unesc.net \\ Universidade do Extremo Sul Catarinense \\ BONETTI, Anderson Vendelino - avbonetti@gmail.com \\ Universidade do Extremo Sul Catarinense
}

\begin{abstract}
RESUMO: A chuva é um dos fatores meteorológicos que apresenta grande variação espacial e temporal. Diversos trabalhos ao ar livre são afetados de forma direta e indireta pela sua ausência ou excesso de precipitação. Este trabalho tem como objetivo caracterizar a distribuição sazonal e espacial da precipitação mensal e anual no Estado de Santa Catarina. Foram utilizados os dados de precipitação diária do período de 1970 a 2012 de 92 estações pluviométricas distribuídas no estado de Santa Catarina. Para estimar a precipitação provável em período mensal foi usada a distribuição gama e para a precipitação anual foram avaliadas as distribuições normal e gama. A aderência das séries de precipitação às distribuições de probabilidade foi avaliada pelo teste de Kolmogorov-Smirnov, ao nível de significância de 5\%. Para representar a variação espacial e sazonal da precipitação foram gerados mapas das variáveis analisadas usando o software ArcGIS. Foram determinados os mapas de precipitação e anual com probabilidades de $25 \%$, 50\% e $75 \%$, em que se pode observar a variação sazonal e também espacial da precipitação no estado de Santa Catarina. Com base nos dados, observou-se que a distribuição Gama se mostrou adequada para estimar as probabilidades de chuva mensal. Para as séries de precipitação anual, embora ambas distribuições foram consideradas adequadas verificou-se que em $75 \%$ das estações o ajuste obtido com a distribuição gama foi melhor que a distribuição normal. A precipitação mensal e anual apresenta grande variação espacial e sazonal no estado de Santa Catarina. Nos meses de outubro a março as maiores precipitações mensais ocorrem na região do litoral norte e menor no litoral sul. Nos meses de abril a setembro observa-se maiores precipitações na região oeste do estado.
\end{abstract}

Palavras-Chave: Precipitação; Teste Kolmogorov-Smirnov; Distribuição Gama; Probabilidade.

MONTHLY AND ANNUAL PROBABLE RAINFALL IN SANTA CATARINA STATE

ABSTRACT: Rain is one of the meteorological factors has great spatial and temporal variation. Several outdoor jobs are affected directly and indirectly by its absence or excess rainfall. This work aims to characterize the seasonal and spatial distribution of monthly and annual rainfall in the State of Santa Catarina. Were used daily rainfall data for the period 1970-2012 from 92 rainfall stations distributed in the state of Santa Catarina. To estimate the probable rainfall in monthly period was used for the gamma distribution and for the annual rainfall the normal and gama distributions were evaluated. The adherence of rainfall at 
probability distributions series was evaluated by the Kolmogorov-Smirnov test at a significance level of $5 \%$. To represent the spatial and seasonal variation in rainfall maps of the variables analyzed using ArcGIS software were generated. Were determined monthly and annual precipitation maps with probabilities of $25 \%, 50 \%$ and $75 \%$, in which one can observe the seasonal and spatial variability of rainfall in the state of Santa Catarina. Based on the data, it was observed that the Gamma distribution was adequate to estimate the probabilities of monthly rainfall. For the series of annual rainfall, although both distributions were considered adequate it was found that $75 \%$ of the stations the adjustment obtained with the gamma distribution was better than normal distribution. The monthly and annual rainfall shows large spatial and temporal variations in the state of Santa Catarina. In the months from October to March the highest monthly rainfall occurs in the north and lower south coast on the coastal region. In the months from April to September the rainfall is observed in the western region of the state

Key-Words: Precipitation; Kolmogorov-Smirnov test, gama distribution; probability

\section{INTRODUÇÃO}

A precipitação pluviométrica é um dos elementos meteorológicos que exerce maior influência sobre as condições ambientais e em quase todas as atividades produtivas desenvolvidas no campo. Diversos trabalhos de engenharia são afetados de forma direta ou indireta, tanto pela ocorrência da chuva, como por sua ausência. Segundo Silva et al. (2003) a precipitação é a variável meteorológica que influencia diretamente no balanço hídrico de uma região, podendo-se por meio dela determinar o excesso ou escassez de chuva de uma determinada região. A chuva é um dos fatores meteorológicos que apresenta grande variação espacial e temporal. A distribuição e a variação da precipitação, no tempo e no espaço, são as principais características climáticas de uma região (KELLER FILHO et al., 2006).

Devido esta importância da chuva nas várias áreas, existe um grande esforço no sentido de medir a quantidade de chuva bem como prever suas ocorrências nos mais variados locais. Dourado Neto et al. (2005) ressaltam que o estudo temporal das distribuições de variáveis climáticas é necessário para compreender os fenômenos meteorológicos, determinando seus padrões de ocorrência e permitindo uma previsibilidade razoável do comportamento climático de uma região, o que é uma ferramenta de grande valor para o planejamento e gestão de inúmeras atividades agropecuárias e humanas. Queiroz et al. (2001) salientam que os conhecimentos referentes ao regime de chuva de uma determinada região contribuem para a tomada de decisões em diversas áreas estratégicas para o desenvolvimento econômico e social do País, 
como pro exemplo a geração de energia elétrica, defesa civil e algumas atividades agrícolas e industriais. Souza et al. (2006) e Martin et al. (2008) destacam a importância de se estudar essa variável meteorológica com objetivo de mostrar que se pode prevenir vários transtornos que a chuva possa causar, além de servir de orientação para a determinação do calendário agrícola pelos agricultores possibilitando também o planejamento e desenvolvimento das atividades agrícolas regionais que estão pautadas no comportamento da precipitação pluvial.

Algumas características de precipitação de um local podem ser extraídas da análise dos registros do que aconteceu no passado. Entretanto, em vários locais os registros históricos de chuva são relativamente curtos e em muitas situações apresentam falhas, impossibilitando assim inferências estatísticas seguras. Em tais situações pode-se utilizar a modelagem matemática para descrever e fazer inferências desejadas.

Diversas distribuições de probabilidade são utilizadas para modelar a quantidade de precipitação dos períodos chuvosos. Thom (1958)mostrou que a distribuição gama pode ser considerada como a mais adequada para períodos curtos (uma semana, cinco dias, um dia) e nas ultimas décadas vários trabalhos foram realizados aplicando a distribuição gama na estimativa da chuva mensal ou em períodos mais curtos, como pode ser verificado em Sediyama et al. (1978), Castro Neto e Silveira (1983), Assad et al. (1993), Soares (1999), Murta et al.(2005), Silva et al. (2007), Lima et al. (2008) entre outros.

Este trabalho tem como objetivo caracterizar a distribuição sazonal e espacial da precipitação mensal e anual no Estado de Santa Catarina.

\section{MATERIAIS E METODOS}

O Estado de Santa Catarina está situado na Região Sul do Brasil e possui uma área oficial de $95.483 \mathrm{~km}^{2}$, com mais $502 \mathrm{~km}^{2}$ de águas territoriais, totalizando $95.985 \mathrm{~km}^{2}$, correspondente a $1,12 \%$ da área brasileira e $16,61 \%$ da Região Sul. O território catarinense está situado entre as latitudes $26^{\circ} 00^{\prime} \mathrm{S}$ e $30^{\circ} 00^{\prime} \mathrm{S}$, e longitudes $48^{\circ} 30^{\prime} \mathrm{W}$ e $54^{\circ} 00^{\prime} \mathrm{W}$ (PANDOLFO et al, 2002).

Os fenômenos relacionados com a dinâmica da atmosfera (frentes meteorológicas) e fatores geográficos, como a orografia, a continentalidade e a maritimidade, são os determinantes das principais características climáticas do extremo sul do Brasil (Vianello, 1991).Segundo a classificação de Köppen (HERRMANN, 1997), o Estado de Santa Catarina foi classificado como o de clima mesotérmico úmido 
(sem estação seca) - Cf, incluindo dois subtipos, Cfa e Cfb. No geral, a precipitação está bem distribuída durante o ano devido às características do relevo e à atuação da Massa de ar Polar Atlântica e da Massa Tropical Atlântica, que por sua constância fazem com que não ocorra uma estação seca (SANTA CATARINA, 1996).

Foram utilizados dados de precipitação diária de 92 estações pluviométricas distribuídas pelo estado de Santa Catarina. Para obter um resultado com mais precisão no momento da interpolação foram usado dados pluviométricos na região de fronteira com os estados vizinhos do Paraná (38 estações) e do Rio Grande do Sul (11 estações).

As estações pluviométricas, com código (ANA, 2009) e município onde se localizam, estão citadas na Tabela 1 . Neste estudo foram utilizados os dados diários registrados no período entre 1970 e 2012.

Tabela 1 - Estações pluviométricas selecionadas para estudo de chuvas intensas de Santa Catarina.

\begin{tabular}{|c|c|c|c|c|c|c|c|}
\hline $\mathrm{N}^{\circ}$ & Código & Município & UF & No & Código & Município & UF \\
\hline 1 & 02648014 & Joinville & SC & 71 & 02752005 & Concórdia & $\mathrm{SC}$ \\
\hline 2 & 02648020 & Araquari & SC & 72 & 02753006 & Palmitos & SC \\
\hline 3 & 02648027 & Garuva & $\mathrm{SC}$ & 73 & 02753013 & Mondaí & SC \\
\hline 4 & 02648028 & Araquari & SC & 74 & 02848000 & Armazém & SC \\
\hline 5 & 02649002 & Pomerode & $\mathrm{SC}$ & 75 & 02848006 & São Martinho & SC \\
\hline 6 & 02649003 & Benedito Novo & SC & 76 & 02848007 & Imbituba & SC \\
\hline 7 & 02649004 & Timbó & SC & 77 & 02849000 & Tubarão & SC \\
\hline 8 & 02649005 & Indaial & SC & 78 & 02849001 & Orleans & SC \\
\hline 9 & 02649007 & Blumenau & $\mathrm{SC}$ & 79 & 02849002 & São Ludgero & SC \\
\hline 10 & 02649013 & Corupá & SC & 80 & 02849004 & Araranguá & SC \\
\hline 11 & 02649054 & Itaiópolis & SC & 81 & 02849006 & Forquilhinha & SC \\
\hline 12 & 02649055 & RioNegrinho & SC & 82 & 02849008 & Grão Pará & SC \\
\hline 13 & 02649056 & Itaiópolis & SC & 83 & 02849009 & Bom Jardim da & SC \\
\hline 14 & 02649057 & Campo Alegre & $\mathrm{SC}$ & 84 & 02849019 & Timbé do Sul & SC \\
\hline 15 & 02649058 & Vitor Meireles & SC & 85 & 02849020 & Jaguaruna & SC \\
\hline 16 & 02650008 & Porto União & $\mathrm{SC}$ & 86 & 02849021 & Urubici & SC \\
\hline 17 & 02650016 & Santa Cecília & SC & 87 & 02849022 & Içara & SC \\
\hline 18 & 02650018 & Canoinhas & SC & 88 & 02849023 & Bom Jardim da & SC \\
\hline 19 & 02651001 & Vargem Bonita & $\mathrm{SC}$ & 89 & 02849024 & Meleiro & SC \\
\hline 20 & 02651036 & Macieira & SC & 90 & 02850004 & Lages & SC \\
\hline 21 & 02651040 & Ponte Serrada & $\mathrm{SC}$ & 91 & 02949001 & Praia Grande & SC \\
\hline 22 & 02652000 & Abelardo Luz & SC & 92 & 02949003 & Sombrio & SC \\
\hline 23 & 02652001 & Ipumirim & SC & 93 & 02548020 & Guaratuba & PR \\
\hline 24 & 02652002 & São Domingos & SC & 95 & 02549076 & Campo do & PR \\
\hline 25 & 02652021 & Jardinópolis & SC & 96 & 02548053 & Guaratuba & PR \\
\hline 26 & 02652031 & S. Lourenço do & SC & 97 & 02550005 & Mallet & PR \\
\hline 27 & 02653001 & Campo Erê & SC & 98 & 02550017 & São Mateus do Sul & PR \\
\hline 28 & 02653002 & Dionísio & SC & 99 & 02550020 & Antônio Olinto & PR \\
\hline 29 & 02653003 & Modelo & SC & 100 & 02649006 & Rio Negro & PR \\
\hline
\end{tabular}




\begin{tabular}{|c|c|c|c|c|c|c|c|}
\hline 30 & 02653004 & Romelândia & SC & 101 & 02649021 & Rio Negro & PR \\
\hline 31 & 02653005 & São José do & $\mathrm{SC}$ & 102 & 02650005 & São Mateus do Sul & PR \\
\hline 32 & 02653007 & Saudades & SC & 103 & 02650006 & São Mateus do Sul & PR \\
\hline 33 & 02653013 & Palma Sola & SC & 104 & 02651000 & União da Vitória & PR \\
\hline 34 & 02748000 & Brusque & SC & 105 & 02651003 & General Carneiro & PR \\
\hline 35 & 02748001 & Major Gercino & SC & 106 & 02651004 & Porto Vitória & PR \\
\hline 36 & 02748003 & Angelina & SC & 107 & 02651005 & União da Vitória & PR \\
\hline 37 & 02748016 & Antônio Carlos & SC & 108 & 02651010 & General Carneiro & PR \\
\hline 38 & 02748017 & Paulo Lopes & SC & 109 & 02651013 & Bituruna & PR \\
\hline 39 & 02748018 & São Bonifácio & SC & 110 & 02651016 & União da Vitória & PR \\
\hline 40 & 02748019 & Gov. Celso & SC & 111 & 02651020 & Bituruna & PR \\
\hline 41 & 02749000 & Apiuna & SC & 112 & 02651023 & Bituruna & PR \\
\hline 42 & 02749001 & Ibirama & SC & 113 & 02651026 & General Carneiro & PR \\
\hline 43 & 02749002 & Ituporanga & SC & 114 & 02651029 & Palmas & PR \\
\hline 44 & 02749003 & Taió & SC & 115 & 02651031 & Palmas & PR \\
\hline 45 & 02749005 & Ibirama & SC & 116 & 02651035 & Palmas & PR \\
\hline 46 & 02749006 & Pouso Redondo & SC & 117 & 02651043 & Palmas & PR \\
\hline 47 & 02749007 & Alfredo Wagner & SC & 118 & 02652007 & Coronel Vivida & PR \\
\hline 48 & 02749012 & Anitápolis & SC & 119 & 02652009 & Pato Branco & PR \\
\hline 49 & 02749013 & Trombudo & SC & 120 & 02652010 & Palmas & PR \\
\hline 50 & 02749015 & Major Gercino & $\mathrm{SC}$ & 121 & 02652011 & Mariópolis & PR \\
\hline 51 & 02749016 & Apiuna & SC & 122 & 02652012 & Vitorino & PR \\
\hline 52 & 02749017 & Ituporanga & SC & 123 & 02652013 & Pato Branco & PR \\
\hline 53 & 02749020 & Rancho & SC & 124 & 02652015 & Clevelândia & PR \\
\hline 54 & 02749027 & Anitápolis & $\mathrm{SC}$ & 125 & 02652022 & Mangueirinha & PR \\
\hline 55 & 02749031 & Lages & SC & 126 & 02652025 & Vitorino & PR \\
\hline 56 & 02749033 & Vidal Ramos & SC & 127 & 02653009 & Sto Antônio do & $\mathrm{PR}$ \\
\hline 57 & 02749034 & Leoberto Leal & $\mathrm{SC}$ & 128 & 02653020 & Salgado Filho & PR \\
\hline 58 & 02749037 & Alfredo Wagner & SC & 129 & 02653021 & Barracão & PR \\
\hline 59 & 02749039 & Rio do Sul & SC & 130 & 02653023 & Flor da Serra do & PR \\
\hline 60 & 02750001 & Campo Belo do & SC & 131 & 02751006 & Paim Filho & RS \\
\hline 61 & 02750007 & Lages & SC & 132 & 02751008 & Maximiliano de & RS \\
\hline 62 & 02750008 & São José do & SC & 133 & 02751015 & Barracão & RS \\
\hline 63 & 02750009 & Curitibanos & SC & 134 & 02751018 & Marcelino Ramos & RS \\
\hline 64 & 02750010 & Curitibanos & SC & 135 & 02752017 & Itatiba do Sul & RS \\
\hline 65 & 02750012 & Curitibanos & SC & 136 & 02752021 & Gaurama & RS \\
\hline 66 & 02750014 & Taió & SC & 137 & 02753002 & Frederico & RS \\
\hline 67 & 02750020 & São José do & SC & 138 & 02753019 & Iraí & RS \\
\hline 68 & 02751001 & Anita Garibaldi & SC & 139 & 02850006 & Bom Jesus & RS \\
\hline 69 & 02751004 & Joaçaba & SC & 140 & 02851043 & Esmeralda & RS \\
\hline 70 & 02751012 & Capinzal & SC & 141 & 02950038 & Terra de Areia & RS \\
\hline
\end{tabular}

Para cada estação pluviométrica foram determinados os totais mensais e anuais de precipitação. Para estimar a precipitação mensal provável, foi utilizada a distribuição Gama, que tem como função densidade de probabilidade:

$$
f . d . p=f(x)=\frac{1}{\Gamma(\gamma) \beta^{\gamma}} x^{\gamma-1} e^{-\frac{x}{\beta}}
$$


comy e $\beta>0$

onde $\Gamma(\mathrm{Y})$ é a função Gama

Os parâmetros da distribuição gama foram estimados pelo método dos Momentos, usando as expressões:

$$
\begin{aligned}
& \beta=\frac{s^{2}}{\bar{x}}(2) \\
& \gamma=\frac{\bar{x}^{2}}{s^{2}}(3)
\end{aligned}
$$

Para os totais anuais de precipitação também foi testada a aderência à distribuição normal, que tem como função densidade de probabilidade é:

$$
f(x)=\frac{1}{\sigma \sqrt{2 \pi}} e^{\frac{-(x-\mu)^{2}}{2 \sigma^{2}}} \infty<X<+\infty(4)
$$

sendo e os parâmetros da distribuição

A aderência dos dados de precipitação total mensal e anual às distribuições ajustadas foi avaliada com o teste de Kolmogorov-Smirnov, consiste em comparar os desvios máximos entre as frequências observadas e as frequências (probabilidades) calculadas, isto é:

$$
\mathrm{D}=\max \left(\mathrm{F}_{\mathrm{obs}}-\mathrm{F}_{\text {esp }}\right)
$$

O valor de $D$ foi comparado com o valor crítico $\left(D_{\text {crit }}\right)$ para o nível de significância de $5 \%$.

\section{RESULTADOS E DISCUSSÃO}

Os valores dos desvios máximos (Dmax) do teste de KolmogorovSmirnov para a aderência das séries de precipitações mensais à distribuição Gama ajustada são apresentados na Figura 1. Na Figura 2 constam os Box-Plots dos valores de Dmax para a distribuição Gama e Normal referente a aderência das séries de precipitação anual.

Os menores valores observados foram na ordem de $5 \%$ (Dmax $=$ $0,05)$ e na grande maioria das estações essa diferença foi inferior a $10 \%$ $($ Dmax $<0,10)$. Para todas as estações estudadas os valores de Dmax foram inferiores aos valores críticos de $5 \%$ de significância (Dcrit), que para cujo valor depende do tamanho da série. Para a série de 43 anos o 
valor crítico é de Dcrit $=0,207$. Observa-se que somente três estações apresentaram Dmax superior a este valor, no entanto eram estações com menor tamanho da série.

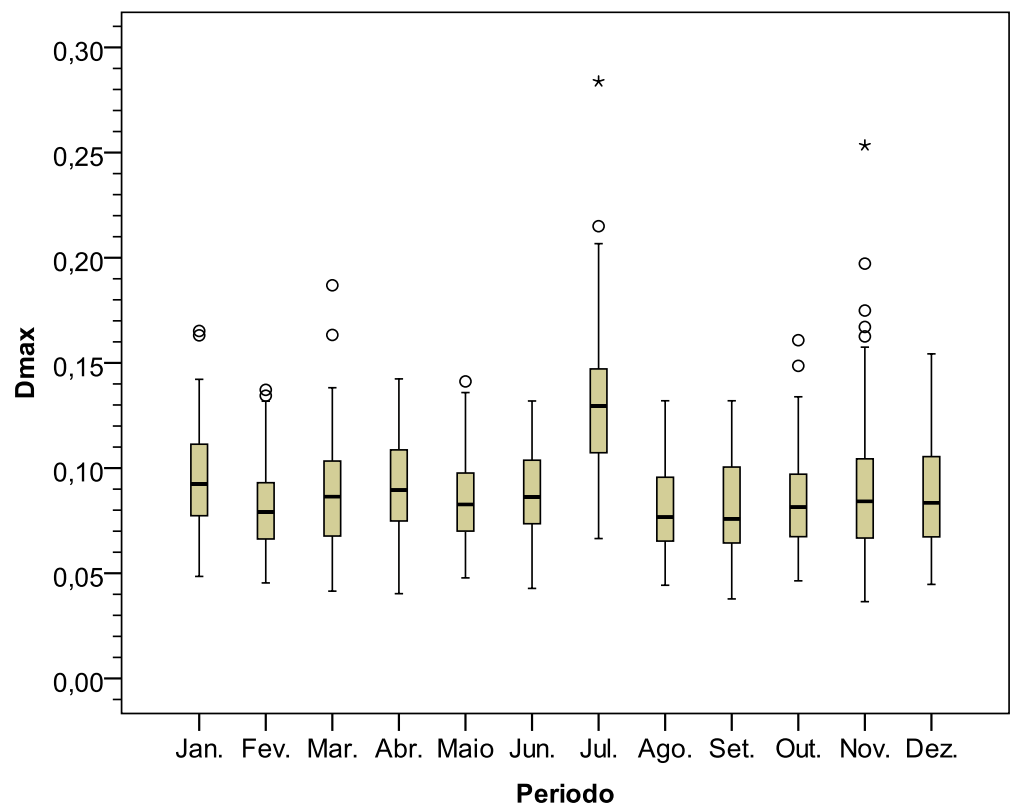

Figura 1 - Box-Plots dos valores de Dmax do teste de Kolmogorov-Smirnov para a aderência das séries de precipitações mensais a distribuição Gama ajustada.

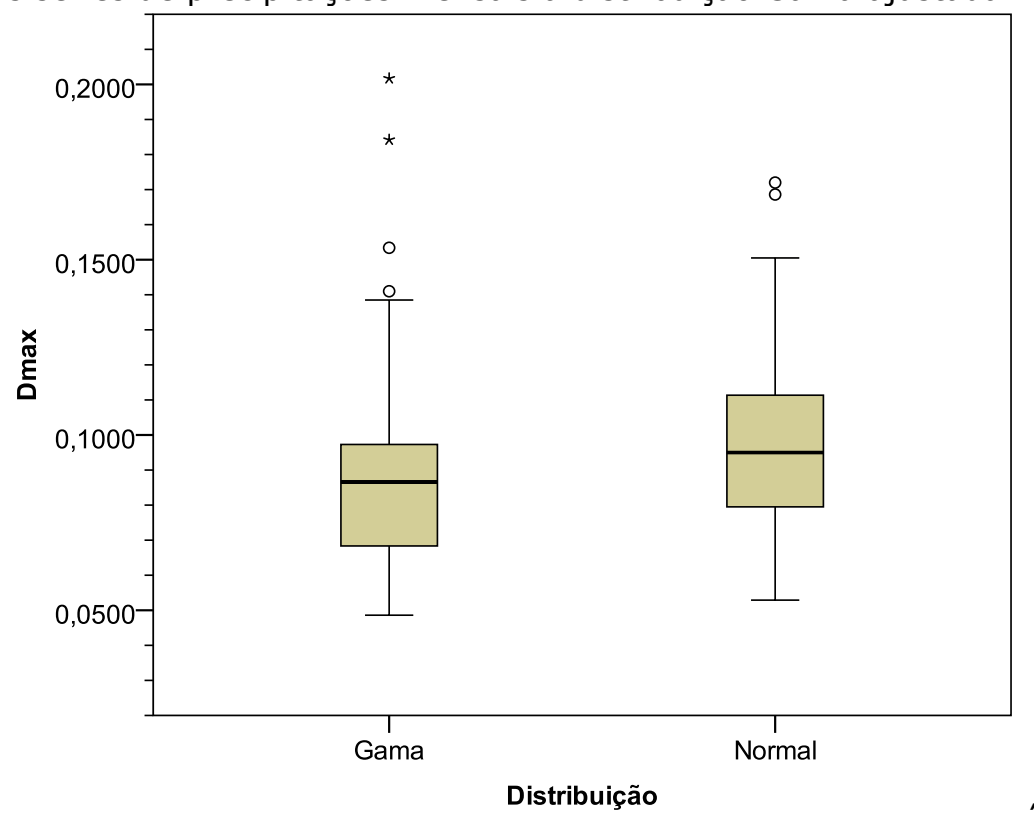

Figura 2 - Box-Plots dos valores de Dmax do teste de Kolmogorov-Smirnov para a aderência das séries de precipitações anuais a distribuição Gama e Normal.

Observa-se também, que no mês de julho foram obtidos maiores valores de Dmax, indicando pior aderência dos dados de precipitação 
mensal à distribuição ajustada. Isto pode ter ocorrido devido a alta assimetria desta série e possível presença de valores extremos que prejudicaram o ajuste da distribuição de frequência dos valores de precipitação mensal.

Vários autores também encontraram ajustes da Distribuição Gama em suas pesquisas em diversos locais, destacando-se os trabalhos de Araújo et al.(2001), Murta et al. ( 2005), Longo et al. (2006), Fietz. et al. (2008), Moreira et al . (2010) e Martins et al. (2010).

Das 92 estações pluviométricas analisadas em Santa Catarina observou-se que em 69 (75\%) (Figura 2) o menor valor de Dmax foi obtido com a distribuição Gama e assim esta foi utilizada também para estimar a precipitação anual provável.

O valor de precipitação com probabilidade de $75 \%$ tem sido indicado em vários trabalhos como critério para dimensionamento de projetos agrícolas. Segundo Mello et al. (2001), o conhecimento prévio da lâmina provável a precipitar, garante maior segurança no planejamento de sistemas de irrigação suplementar e até mesmo na expansão da produção agrícola, permitindo maior eficiência no aproveitamento de recursos hídricos. Já Bernardo (1995) afirma que o nível de 75 a $80 \%$ de probabilidade de ocorrência de chuva é o mais confiável para dimensionamento de projetos agrícolas ou de irrigação.

Segundo Castro e Leopoldo (1995), no Brasil o parâmetro geralmente utilizado para dimensionamento de sistemas de irrigação é a média pluviométrica. No entanto, ressaltam que a utilização desse parâmetro subestima valores de $50 \%$ de probabilidade. Ainda de acordo com os mesmos autores, a recomendação técnica para elaboração de projetos de irrigação deve ser em níveis entre 75 e $80 \%$ de probabilidade. A utilização da média como parâmetro de dimensionamento pode gerar sub-dimensionamento de sistemas de irrigações ocasionando prejuízos ao agricultor. Segundo Silva et al. (2013), na maioria dos casos, o valor médio da precipitação está entre 40 e $50 \%$ de probabilidade de ocorrência; esse valor está abaixo dos indicados para uso em planejamento de sistemas de irrigação que ficam em torno de 75\% (CASTRO \& LEOPOLDO, 1995).

Verificando os resultados da distribuição da precipitação mensal com probabilidade de ocorrência para $75 \%$ (Figuras 3 e 4), observa-se para região Norte do estado, um maior valor de precipitação entre os meses de janeiro a março com média de $470 \mathrm{~mm}$; o mês de setembro apresentou média de $275 \mathrm{~mm}$; novembro e dezembro com média de 375 $\mathrm{mm}$. Nos outros meses, abril a agosto e outubro, as regiões Oeste e Serrana apresentaram maior valor de precipitação, com destaque para o 
mês de outubro, com média de $280 \mathrm{~mm}$. Durante o período monitorado, as regiões do Vale do Itajaí, Grande Florianópolis e Sul Catarinense demonstraram os menores valores de precipitação anual, variando entre $90 \mathrm{~mm}$ até $360 \mathrm{~mm}$.

Segundo Orselli (1991) os menores valores observados no litoral sul de Santa Catarina, refletem a atuação de corrente fria das Malvinas e as modificações locais da circulação atmosférica, determinadas pela passagem livre de ventos vindos do oceano, que na sua rota do mar até as encostas da Serra Geral, perdem umidade. Segundo Monteiro e Furttado (1995) no litoral centro-norte os valores pluviométricos mostram-se relativamente mais elevados. Particularmente, esta região sofre influência direta na Massa Tropical Marítima, fato que pode ser explicado pela forma de relevo adquirido, voltado para a direção da fluência dos ventos originários da Massa Tropical Marítma. Com seu anticiclone localizado na região sudeste do Brasil, os ventos que se originam desta, fluem do nordeste, na região centro-norte catarinense. 


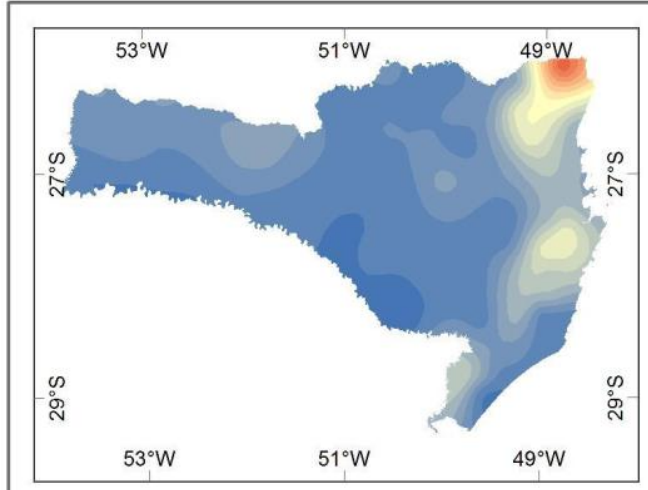

Janeiro - Precipitação (mm)
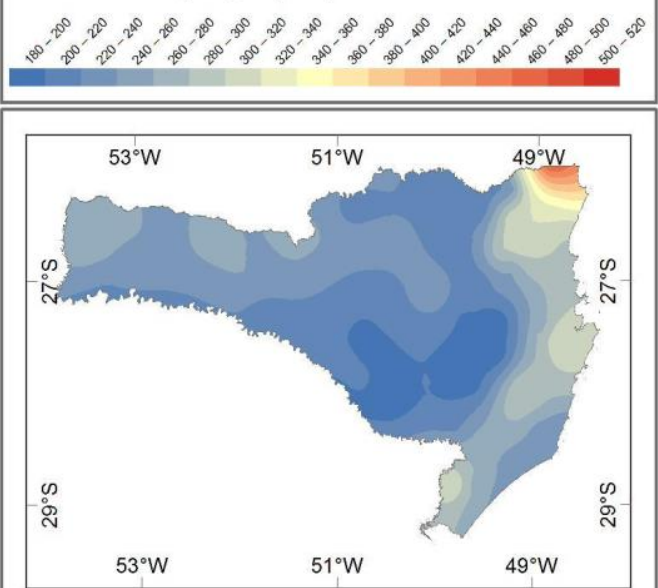

Março - Precipitação (mm)
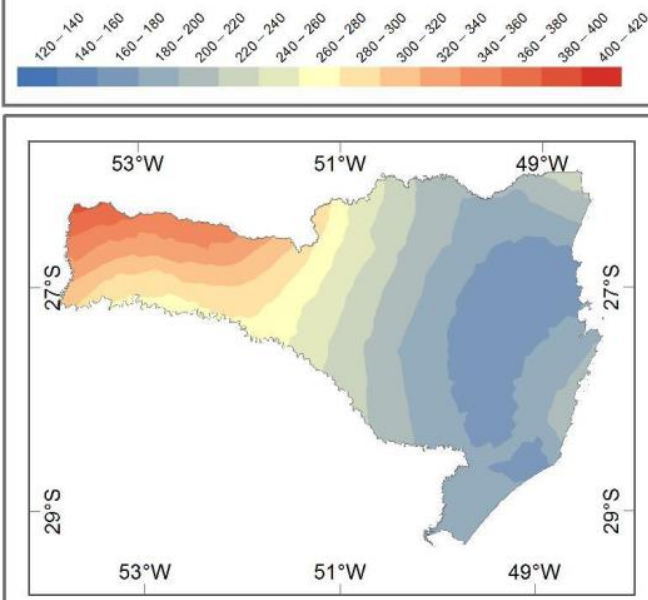

Maio - Precipitação $(\mathrm{mm})$

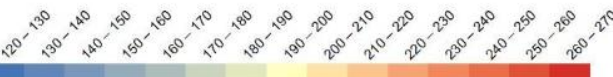

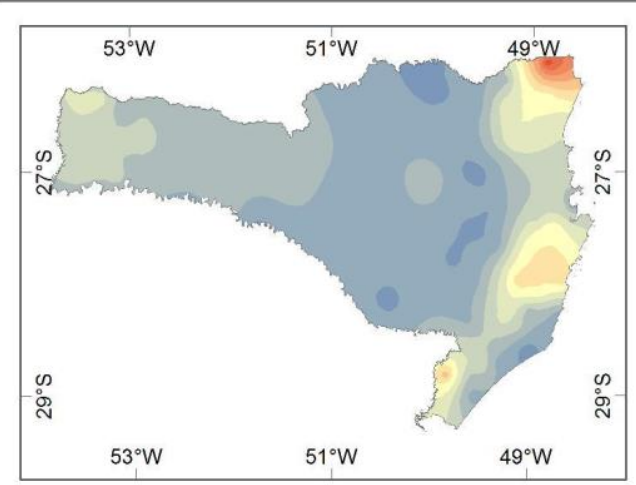

\section{Fevereiro - Precipitação (mm)}

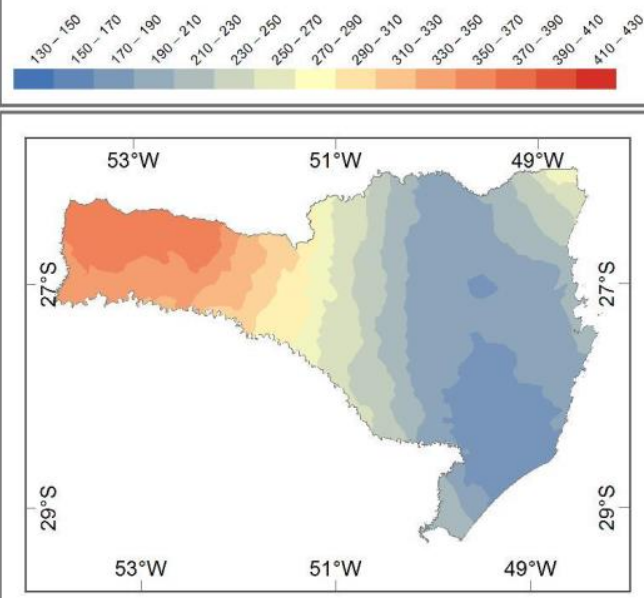

Abril - Precipitação (mm)
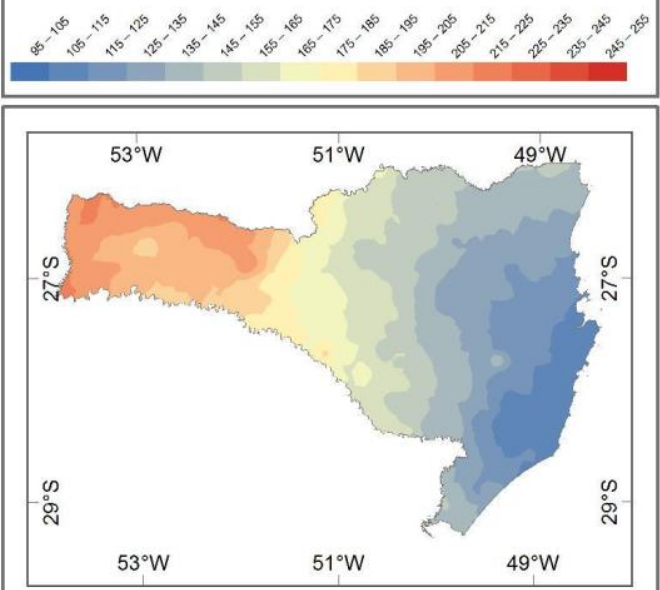

Junho - Precipitação (mm)

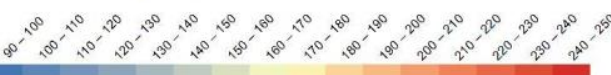

Figura 3 - Distribuição do volume de precipitação mensal com probabilidade de $75 \%$ para os meses de janeiro a junho. 


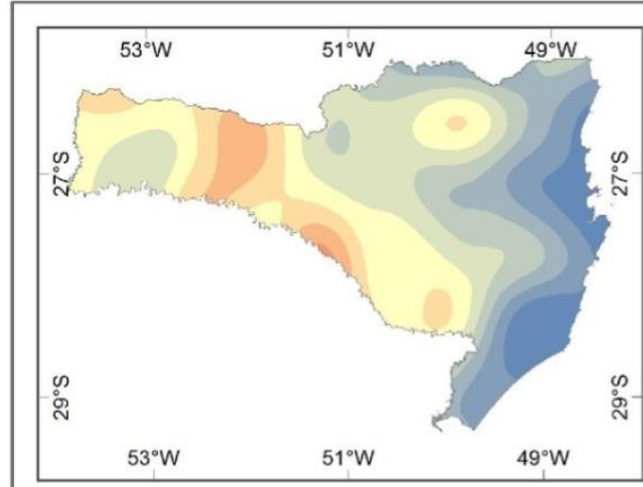

Julho - Precipitação $(\mathrm{mm})$
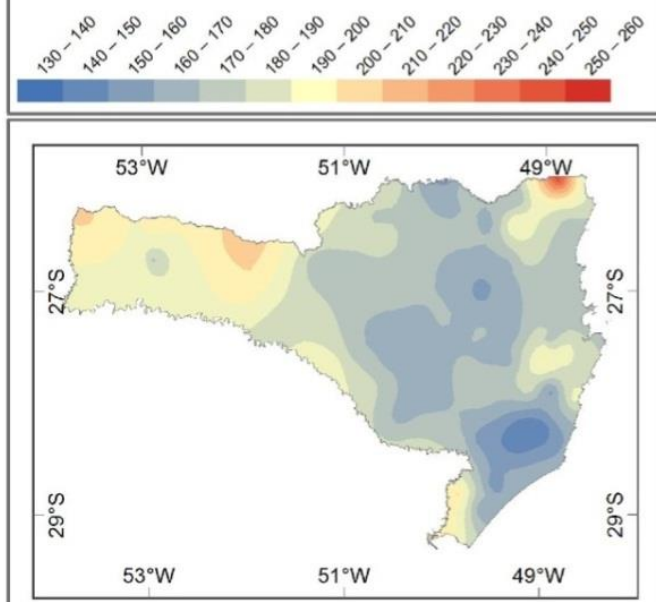

Setembro - Precipitação $(\mathrm{mm})$
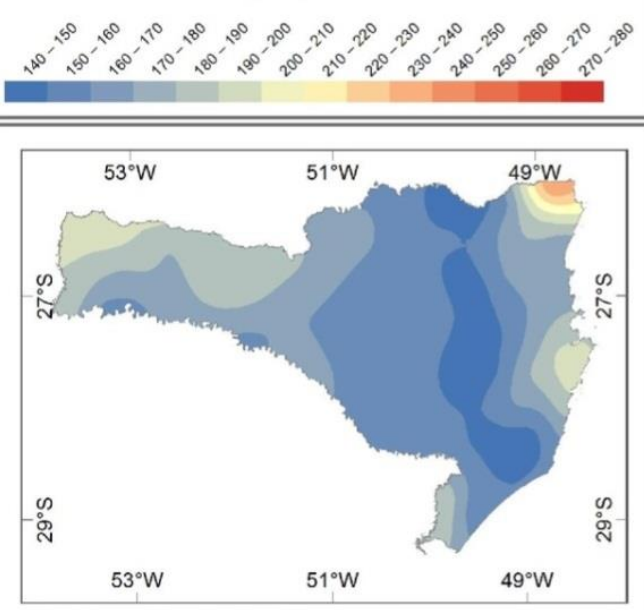

Novembro - Precipitação $(\mathrm{mm})$

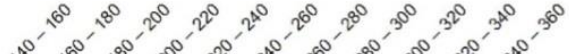

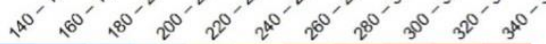

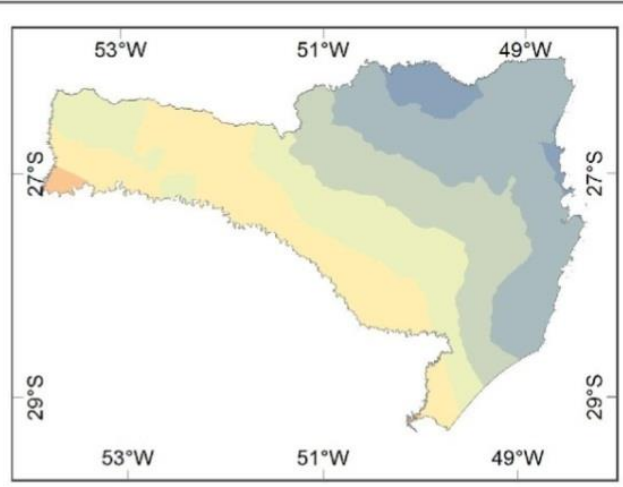

Agosto - Precipitação (mm)

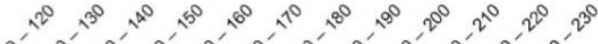

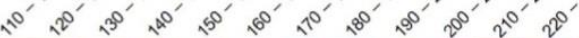

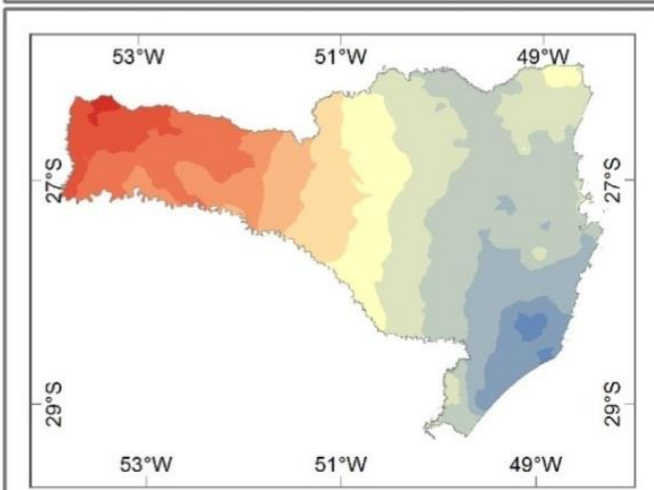

Outubro - Precipitação (mm)
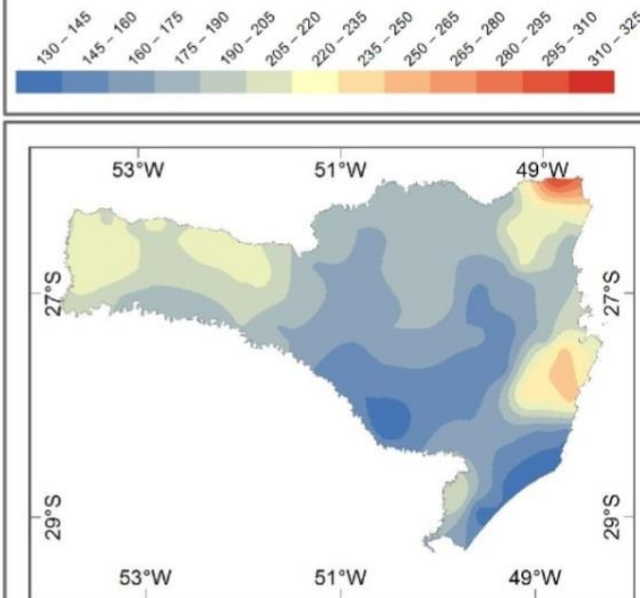

Dezembro - Precipitação $(\mathrm{mm})$

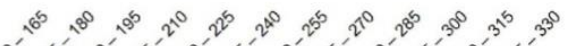

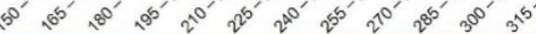

Figura 4 - Distribuição do volume de precipitação mensal com probabilidade de 75 \% para os meses de julho a dezembro.

Com relação a precipitação mensal com probabilidade de ocorrência 
para $50 \%$ (Figura 5 e 6), observa-se para região Norte do estado, um maior valor de precipitação entre os meses de janeiro a março que apresentou uma média de $358 \mathrm{~mm}$; o mês de setembro com média de $275 \mathrm{~mm}$; novembro e dezembro apontando média de $345 \mathrm{~mm}$. As regiões Oeste e Serrana apresentaram maior volume de precipitação, para os meses que compreendem as estações do ano de outono, com média de $175 \mathrm{~mm}$ e inverno com volume de $210 \mathrm{~mm}$.

No mês de outubro, a região Oeste, apresentou o maior valor para o estado, com média de $288 \mathrm{~mm}$. Novamente a região litorânea, compreendida pelas mesorregiões do Vale do Itajaí, Grande Florianópolis e Sul Catarinense demonstraram os menores valores de precipitação anual, variando entre $90 \mathrm{~mm}$ até $360 \mathrm{~mm}$.

Para a precipitação mensal com probabilidade de ocorrência para 25\% (Figuras 7 e 8 ), observa-se para a região Norte do estado um maior valor entre os meses de janeiro a março, com média de $270 \mathrm{~mm}$. Durante o outono e inverno, o valor diminui, passando a ter uma média de $54 \mathrm{~mm}$. Nos meses de novembro e dezembro os valores elevam-se novamente, obtendo um valor médio de $140 \mathrm{~mm}$. A região do Oeste Catarinense apresenta maiores valores de precipitação entre os meses de abril a junho, média de $115 \mathrm{~mm}$ e novamente em outubro e novembro, média de $143 \mathrm{~mm}$. A região litorânea, que compreende as regiões do Vale do Itajaí, Grande Florianópolis e Sul Catarinense nas estações do ano outono e inverno, apresentou valores mínimos médios de $40 \mathrm{~mm}$. A região Serrana apresentou maiores valores de precipitação nos meses mais quentes (janeiro a março e dezembro) $105 \mathrm{~mm}$ e valores médios no restante do ano com $70 \mathrm{~mm}$. As diferentes probabilidades de ocorrência da precipitação mensal de $75 \%, 50 \%$ e $25 \%$, para cada região do estado de Santa Catarina, permitem que qualquer profissional que trabalhe em setores que dependem desta variável planeje suas ações ao longo do ano.

A precipitação total anual apresenta acentuada variação espacial no estado de Santa Catarina (Figura 9). Observa-se que os menores valores de precipitação anual com $25 \%$ de probabilidade ocorrem na região do Litoral Sul do estado, com valores na faixa de 1000 a $1100 \mathrm{~mm}$ e os maiores valores ocorrem na região do Litoral Norte, na faixa de 2300 a $2400 \mathrm{~mm}$. Na região do Planalto estes valores ficam na faixa de 1200 a $1400 \mathrm{~mm}$ aumentando em direção ao Oeste do estado onde atingem valores de 1600 a $1700 \mathrm{~mm}$.

A precipitação anual com probabilidade de $50 \%$ varia de 1300 a $1400 \mathrm{~mm}$ no Litoral Sul do estado a 2600 a $2700 \mathrm{~mm}$ no Litoral Norte e 2000 a 2100 mm no Oeste do Estado. Já a precipitação anual com $25 \%$ de probabilidade varia de 1500 a $1600 \mathrm{~mm}$ no Litoral Sul do estado a 3000 a $3100 \mathrm{~mm}$ no Litoral Norte e 2400 a $2600 \mathrm{~mm}$ no Oeste do estado. 


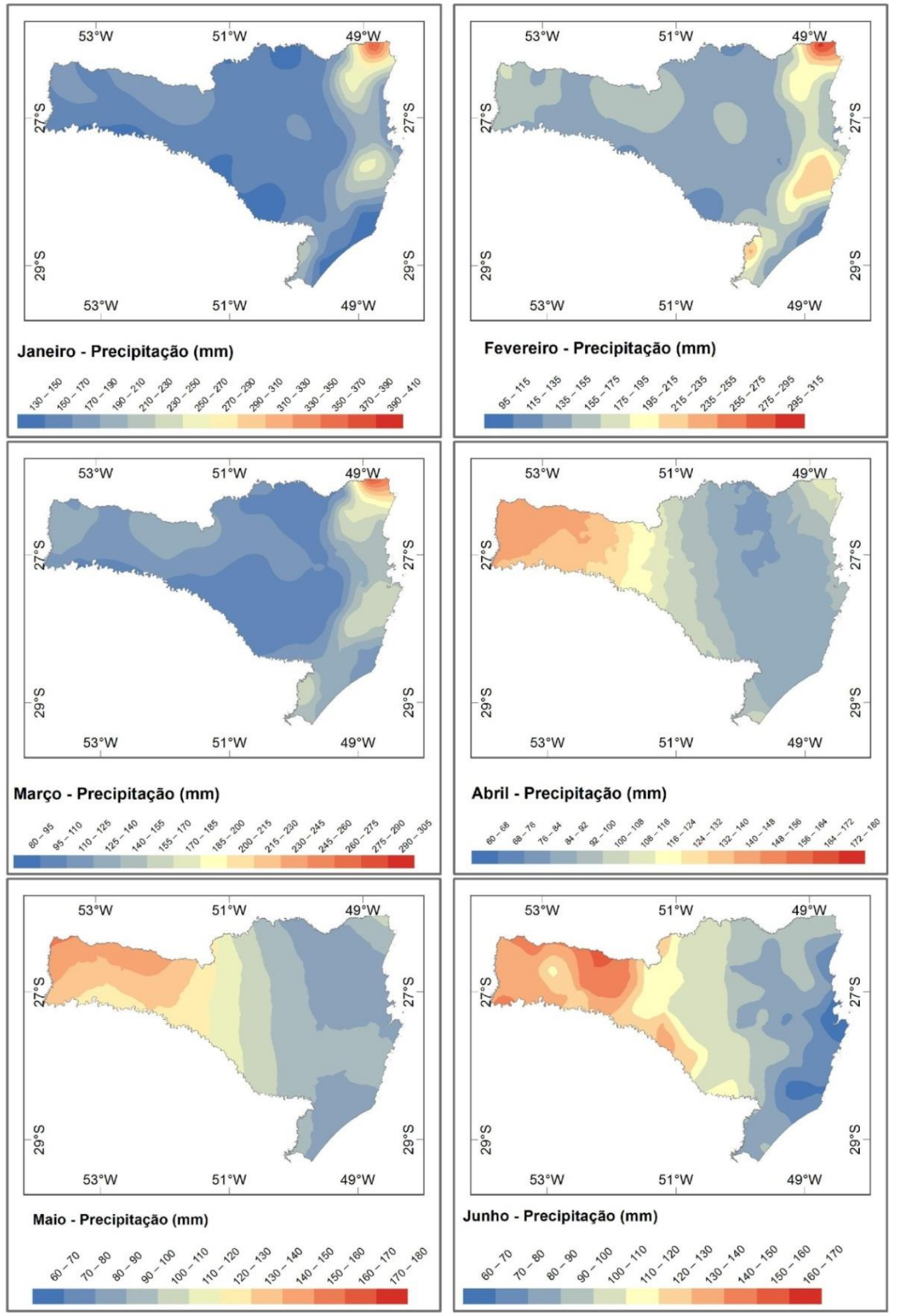

Figura 5 - Distribuição da precipitação mensal com probabilidade de 50 \% para os meses de janeiro a junho. 


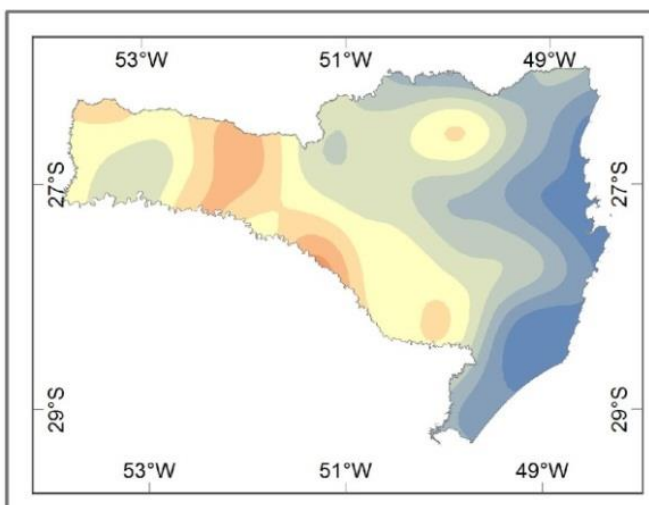

Julho - Precipitação (mm)

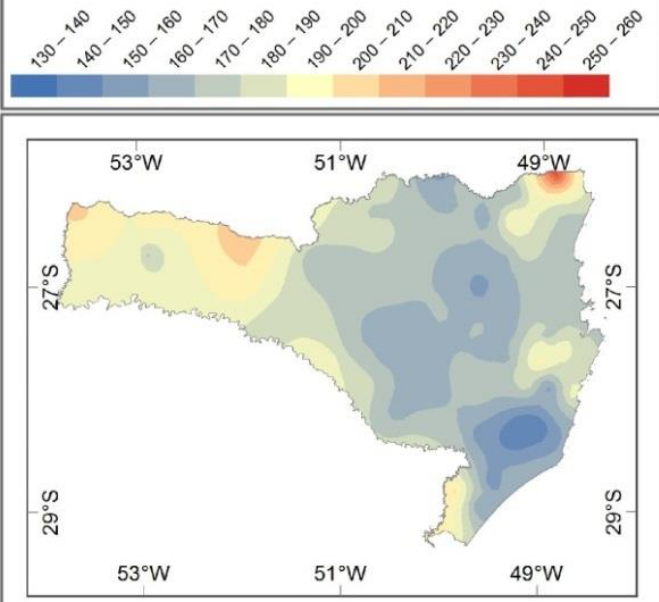

\section{Setembro - Precipitação (mm)}
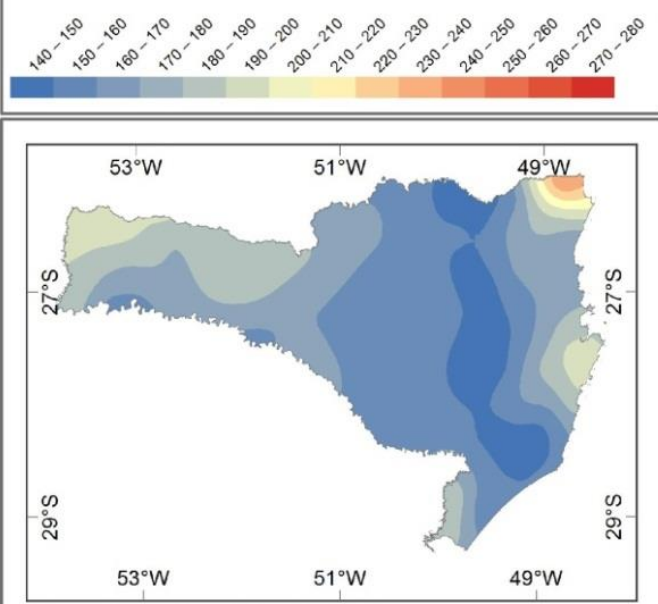

Novembro - Precipitação $(\mathrm{mm})$

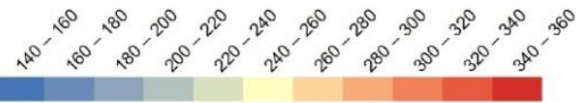

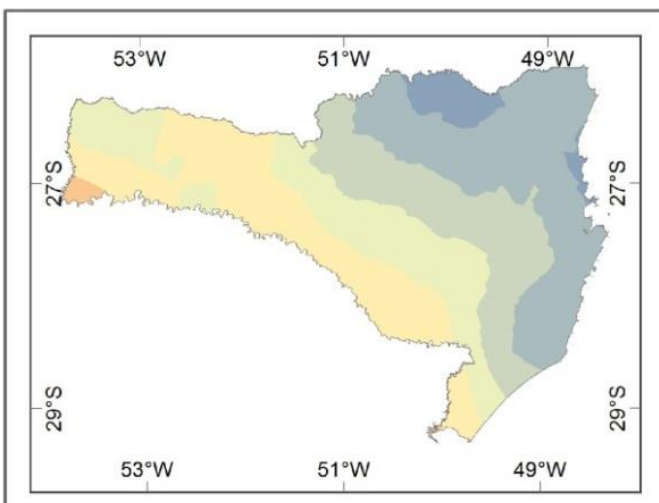

Agosto - Precipitação $(\mathrm{mm})$

$22^{\circ}, 3^{\circ}, 0^{\circ}, 5^{\circ}, 6^{\circ}, 10,10^{\circ}, 9^{\circ}, 2^{\circ}, 2^{\circ}, 2^{\circ}, 3^{\circ}$

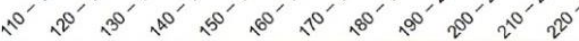

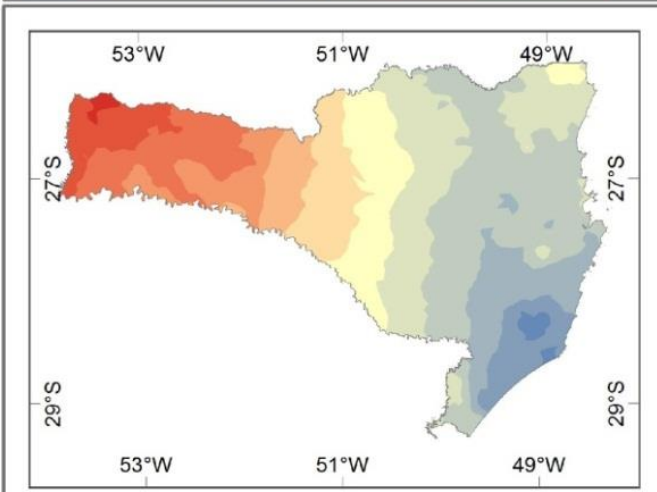

Outubro - Precipitação (mm)

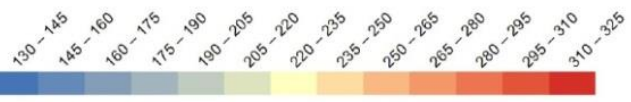

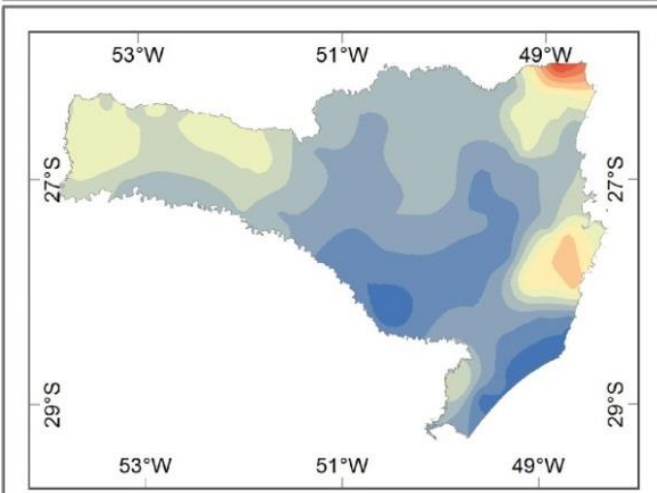

Dezembro - Precipitação (mm)

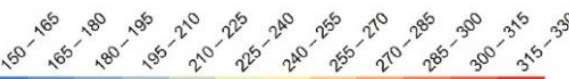

Figura 6 - Distribuição da precipitação mensal com probabilidade de $50 \%$ para os meses de julho a dezembro. 


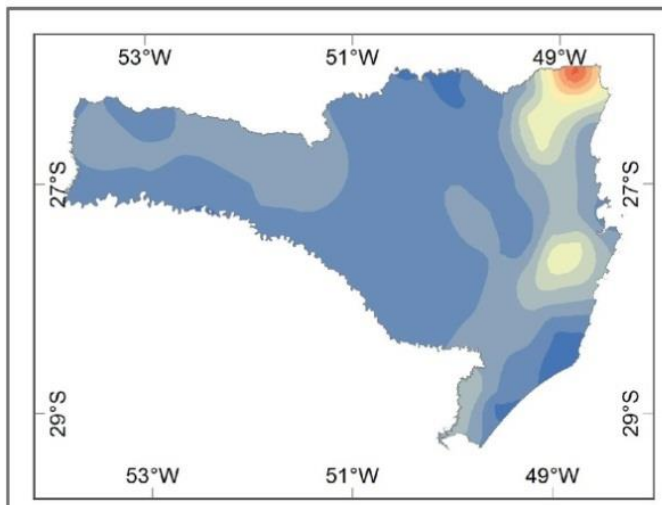

Janeiro - Precipitação (mm)
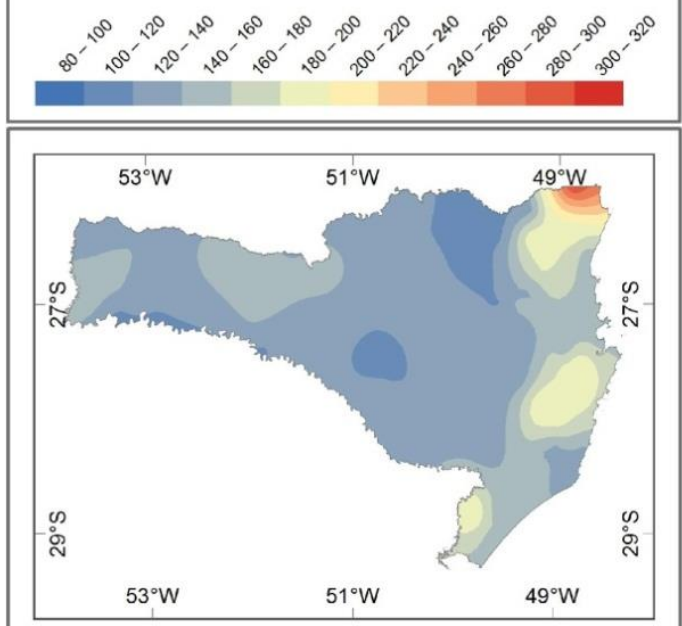

Março - Precipitação (mm)
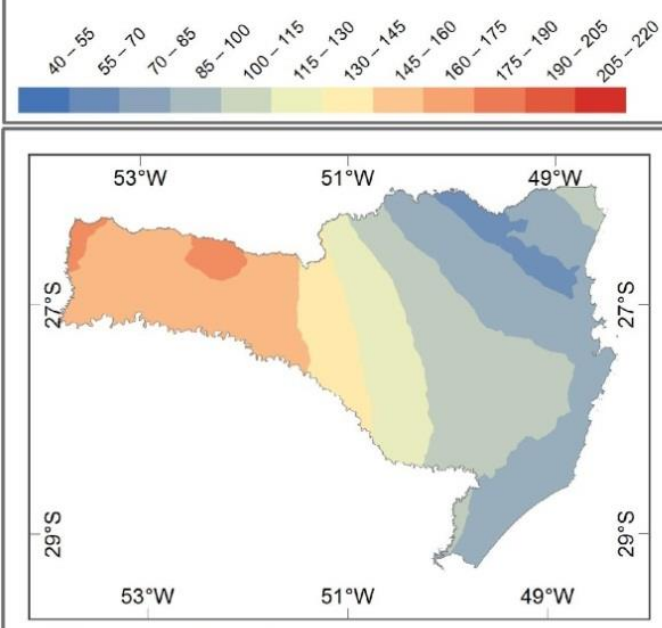

Maio - Precipitação $(\mathrm{mm})$

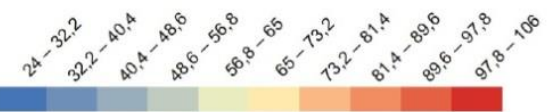

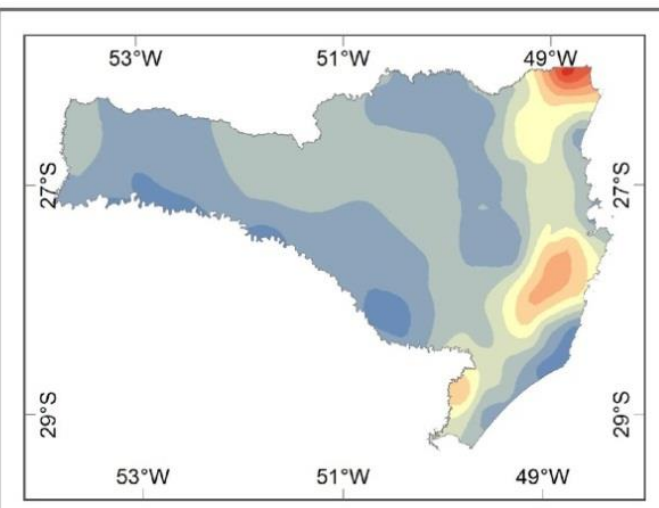

Fevereiro - Precipitação (mm)

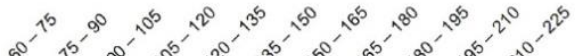

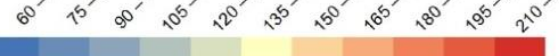

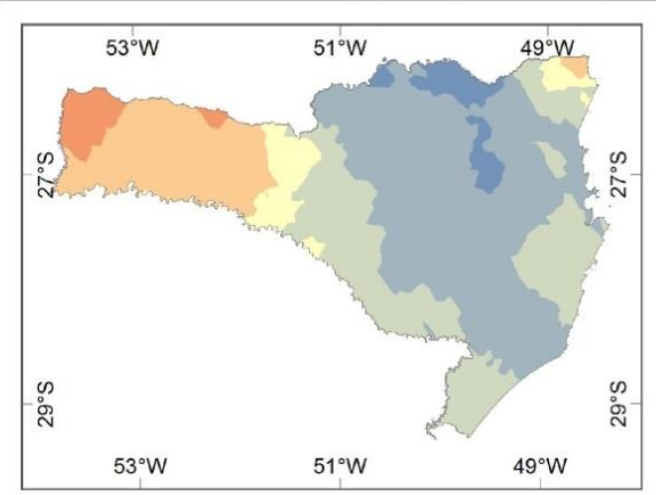

Abril - Precipitação (mm)

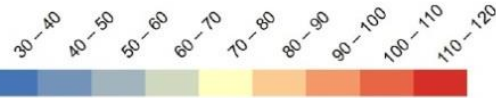

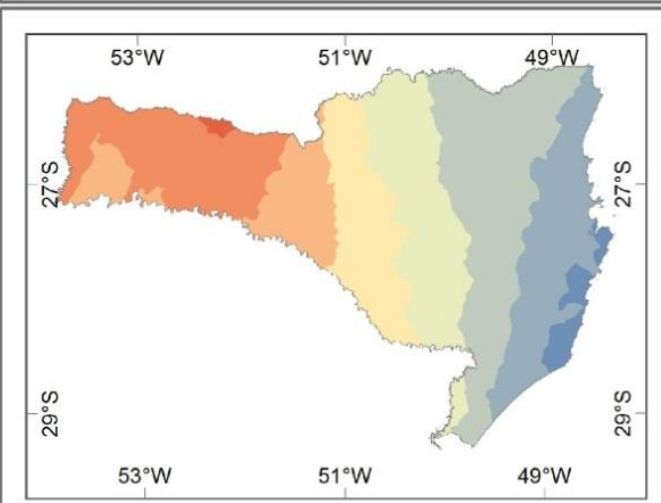

Junho - Precipitação $(\mathrm{mm})$

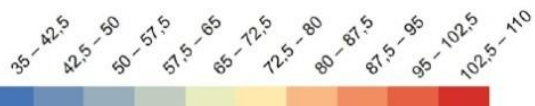

Figura 7 - Distribuição da precipitação mensal com probabilidade de $25 \%$ para os meses de janeiro a junho. 


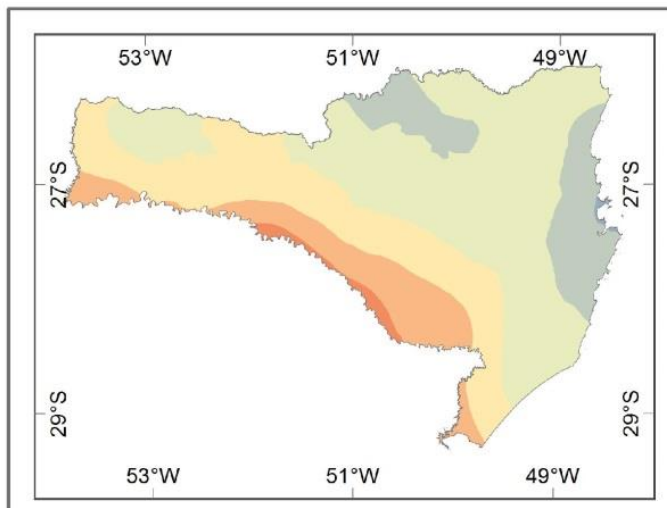

Julho - Precipitação (mm)

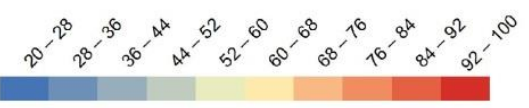

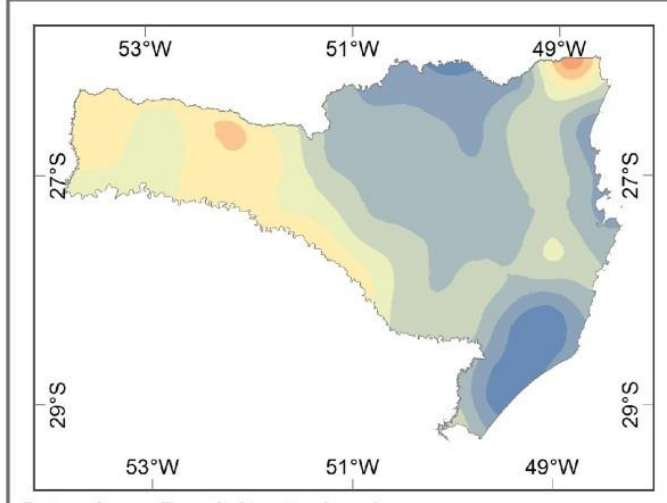

Setembro - Precipitação $(\mathrm{mm})$

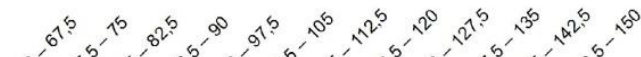

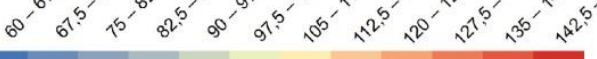

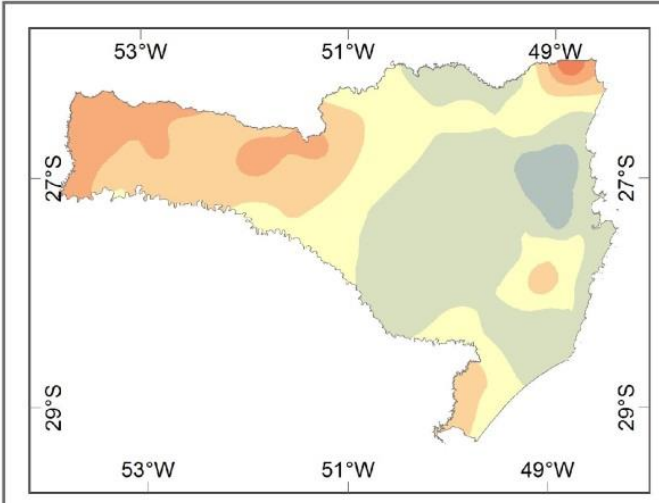

Novembro - Precipitação (mm)

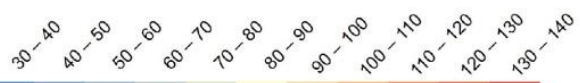

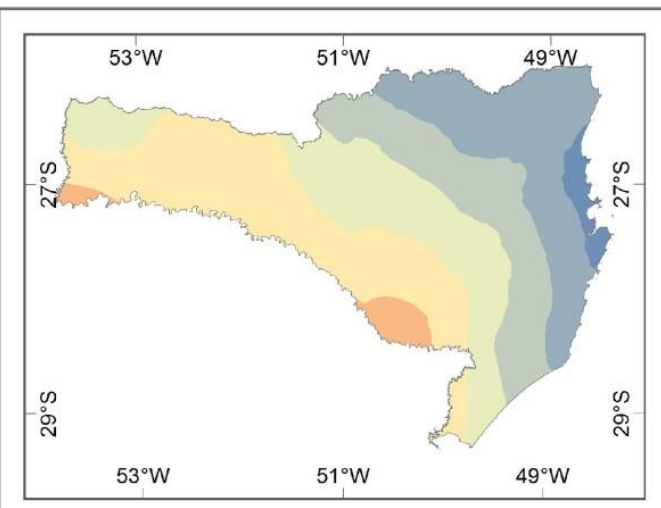

Agosto - Precipitação (mm)

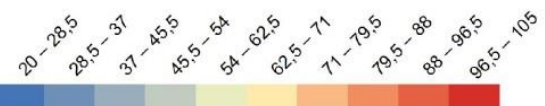

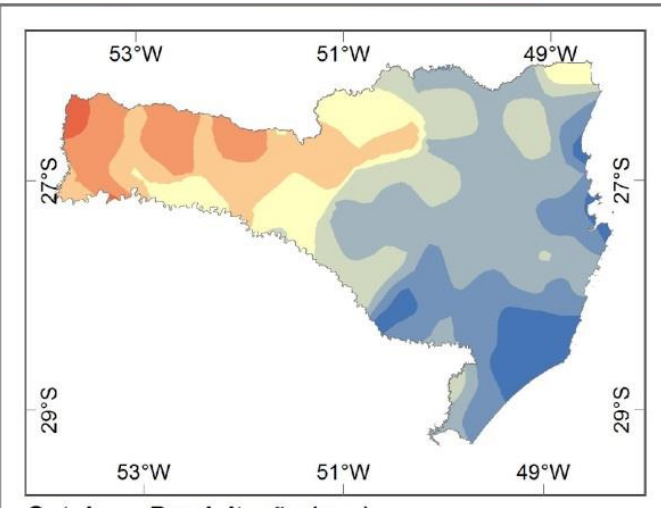

Outubro - Precipitação (mm)

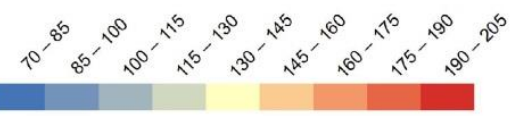

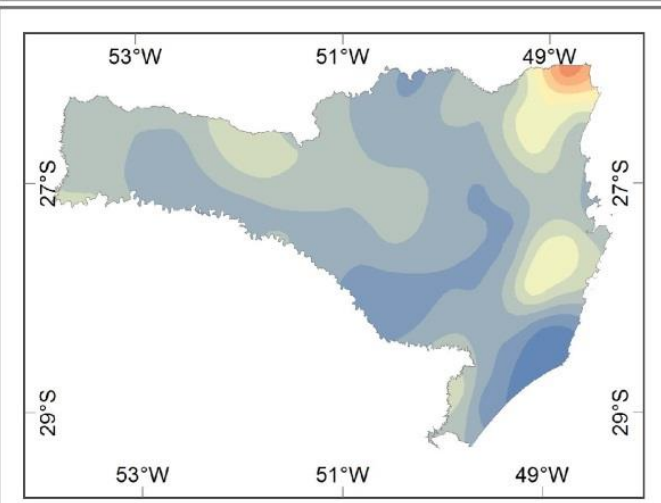

Dezembro - Precipitação $(\mathrm{mm})$

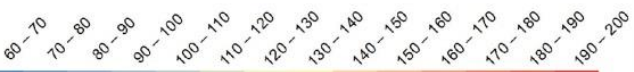

Figura 8 - Distribuição da precipitação mensal com probabilidade de $25 \%$ para os meses de julho a dezembro 


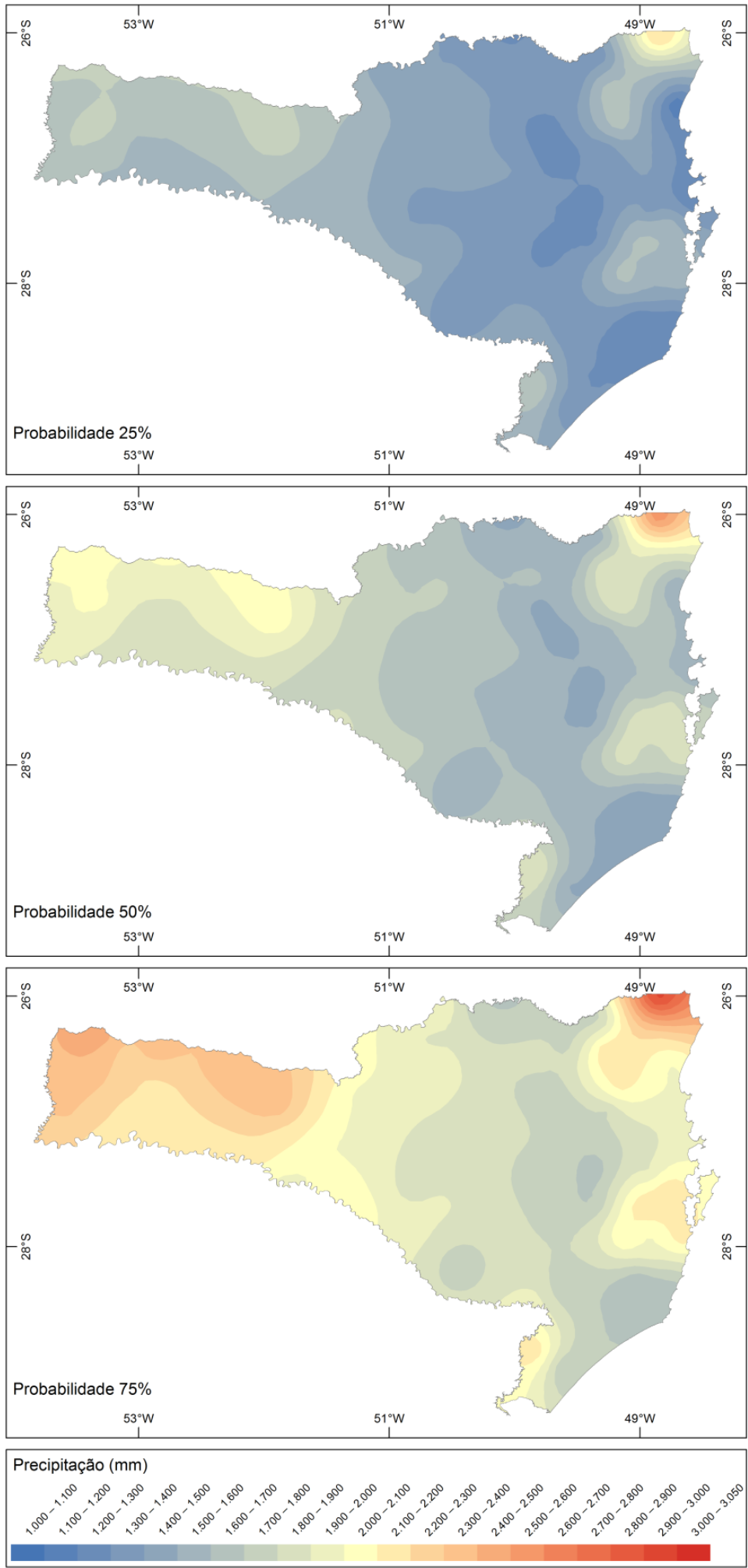

Figura 9. Precipitação total anual de Santa Catarina com probabilidade de $25 \%, 50 \%$ e $75 \%$. 


\section{CONCLUSÕES}

Com base nos resultados das análises dos dados das 92 estações pluviométricas distribuídas pelo estado de Santa Catarina pode-se concluir que:

1- A distribuição gama se mostrou adequada para estimar a probabilidade das precipitações mensais;

2- Para a precipitação total anual a distribuição Gama se mostrou mais adequada que a distribuição normal para a maioria das estações estudadas;

3- Existe uma variação da distribuição das precipitações mensais no território catarinense, onde os maiores valores de precipitação mensal, ocorrem na região do litoral norte entre os meses de novembro a março. Na região do oeste catarinense os maiores valores ocorrem entre os meses de abril a outubro e os menores valores de precipitação ocorrem na região sul catarinense;

4- A elaboração de mapas para o estado de Santa Catarina prevendo o volume de chuva se torna útil no planejamento de atividades que necessitem de água e também no dimensionamento de estruturas de armazenamento das águas pluviais;

\section{REFERENCIAS BIBLIOGRÁFICAS}

Agencia Nacional de Águas (ANA). Inventário das estações pluviométricas. Agencia Nacional de Águas. 2ed. Brasília:SGH, 2009, 332p.

ARAÚJO, W.F.; JÚNIOR, A.S.A.; MEDEIROS, R.D.; SAMPAIO, R. Precipitação pluviométrica mensal provável em Boa Vista, Estado de Roraima, Brasil. Revista Brasileira de Engenharia Agrícola e Ambiental, Campina Grande, v.5, n.3, p.563-567, 2001.

ASSAD, E.D.; SANO, E.E.; MASSUTOMO, E.; CASTRO, L.H.R de; SILVA, F.A.M da. Veranicos na região dos cerrados brasileiros, frequência e probabilidade de ocorrência. Pesquisa Agropecuária Brasileira, Brasília, v. 28, n. 9, p. 9931003, 1993.

BASTIÃO, A.C.; PESSOA, M.J.G.; DALLACORT, R.; CARVALHO, M.A.C. Distribuição temporal e probabilidade de ocorrência de chuva no município de Juína (MT). Revista Brasileira de Climatologia, Curitiba, v.13, p.258-270, 2013.

BOTELHO, V.A.; MORAIS, A.R. Estimativas dos parâmetros de distribuição gama de dados pluviométricos do município de Lavras, Estado de Minas Gerais. Revista Ciência Agrotecnologia, Lavras, v. 23, n. 3, p. 697-706, 1999. 
BERNARDO, S. Manual de irrigação. Viçosa: Imprensa Universitária, 1995. $657 p$.

CASTRO, R; LEOPOLDO, P.R. Ajuste da distribuição gama incompleta na estimativa da precipitação pluviométrica provável para os períodos de 15 e 10 dias da cidade de São Manuel (SP). Energia na Agricultura, Botucatu, v.10, n.1, p.20-28, 1995.

CASTRO NETO, P.; SILVEIRA, J.V. Precipitação provável para Lavras, região sul de Minas Gerais, baseada na função de distribuição Gama. III. Períodos de 10 dias. Ciência Prática, Lavras, n.5, v.2, p.144-151, 1983.

CHILDS, C. Interpolating Surfaces in ArcGIS in ArcGISAnalyst. ArcUser, July - September 2004: 32 - 34.

DOURADO NETO, D.; ASSIS, J.P.; TIMM, L.C.; MANFRON, P.A.; SPAROVEK, G.; MARTIN, T.N. Ajustes de modelos de distribuição de probabilidade a séries históricas de precipitação pluvial diária em Piracicaba-SP. Revista Brasileira de Agrometeorologia, v.13, n.2, p.273-283, 2005.

FIETZ, C.R.; COMUNELlO, É.; CREMON, C.; DALLACORT, R.; PEREIRA, S.B. Estimativa da precipitação provável para o Estado de Mato Grosso. Dourados: Embrapa Agropecuária Oeste, 2008

HERRMANN, M.L.P. Levantamento dos Desastres Naturais Causados pelas Adversidades Climáticas no Estado de Santa Catarina, período 1980 a 1995 1997. 59p. Tese (Doutorado em Geografia). Universidade Federal de Santa Catarina, Florianópolis.

EPAGRI (Empresa de Pesquisa Agropecuária e Extensão Rural de Santa Catarina). Zoneamento Agroecológico e Socioeconômico do Estado de Santa Catarina, 1999. (CD).

ESRI. ArcGIS Desktop: Release 10.2. Redlands, CA: Environmental Systems Research Institute, 2013.

KELLER FILHO, T.; ZULLO JUNIOR, J.: LIMA, P.R.S. de R. Análise da transição entre os dias secos e chuvosos por meio da cadeia Markov de terceira ordem.

Pesquisa Agropecuária Brasileira, Brasília, v.41, n.9, p.1341-1349,2006.

KELMAN, J. Controle de Cheias e Aproveitamentos Hidroelétricos (RBE). Revista Brasileira de Engenharia, Rio de Janeiro, p 56-57, 1987.

KITE, G. W. Frequency and risk analisys in hidrology. Fort Colins, Water Resourses Publications, 1978, v.3, 395p.

LIMA, J.S.S.; SILVA, S.A.; OLIVEIRA, R.B.; CECÍLIO, R.A.; XAVIER, A.C. Variabilidade temporal da precipitação mensal em Alegre - ES. Revista Ciência Agronômica, Fortaleza, v.39, n.2, p.327-332,2008. 
LONGO, A.J.; SAMPAIO, S.C.; SUSZEK. M. Modelo computacional para estimativa das precipitações prováveis utilizando as distribuições de probabilidades gama e log-normal. Revista Varia Scientia, Cascavel, v.6, n.11, p.141-148, 2006.

MARTIN, T.N.; DOURADO NETO, D.; VIEIRA JUNIOR, P.A.; MANFRON, P.A. Homogeneidade espaço temporal e modelos de distribuição para a precipitação pluvial no estado de São Paulo. Revista Ceres, v.55, n.5, p.476-481, 2008.

MARTINS, J.A.; DALLACORT, R.; INOUE, M.H.; SANTI, A.; KOLLING, E.V.;COLLETI, A.J. Probabilidade de precipitação para a microrregião de Tangará da Serra, Estado do Mato Grosso. Pesquisa Agropecuária Tropical, Goiânia, v. 40, n.3, p. 291-296, 2010.

MONTEIRO, M.A.; FURTADO, S.M.A.. O Clima do trecho de Florianópolis-Porto Alegre: uma abordagem dinâmica. In: GEOSUL, n. 19/20, ano $10,1^{\circ} \mathrm{e}$ 20 semestre de 1995 .

MELLO, C.R.; FERREIRA, D.F.; SILVA, A.M.; LIMA, J.M. Análise de modelos matemáticos aplicados ao estudo de chuvas intensas. Revista Brasileira de Ciência do Solo, Viçosa, v.25, n.3, p.693-698,2001.

MOREIRA, O.S.P.; DALLACORT, R.; MAGALHÃES, R.A.; INOUE, M.H.; STIELLER, M.C.; SILVA, D.J.; MARTINS. Distribuição e probabilidade de ocorrências de chuvas no município de Nova Maringá-MT. Revista de Ciências AgroAmbientais, Alta Floresta, Cáceres, v.8, n.1, p.9-20, 2010.

MURTA, R.M.; TEODORO, S.M.; BONOMO, P.; CHAVES, M.A. Precipitação pluvial mensal em níveis de probabilidade pela distribuição gama para duas localidades do sudoeste da Bahia. Ciência e Agrotecnologia, Lavras, v.29, n.5, p.988994, 2005.

QUEIROZ, E.F.; SILVA, R.J.B.; OLIVEIRA, M.C.N. Modelo de análise de regressão periódica da precipitação mensal, da bacia atlântico sudeste, no Estado do Paraná. Pesquisa Agropecuária Brasileira, Brasília, v.36, n.5, p.727-742, 2001

ORSELLI, L. Clima. Atlas de Santa Catarina. Rio de Janeiro: Secretaria de Estado de Coordenação Geral e Planejamento, 1991, 96p.

PANDOLFO, C.; BRAGA, H. J.; SILVA JR, V. P. da; MASSIGNAM, A. M., PEREIRA, E. S.; THOMÉ, V. M. R.; VALCI, F.V. Atlas climatológico do Estado de Santa Catarina. Florianópolis: Epagri, 2002.

SANTA CATARINA. Secretaria de Estado do Desenvolvimento Urbano e Meio Ambiente; Secretaria de Estado do Desenvolvimento Rural e Da Agricultura. Zoneamento da disponibilidade e da qualidade hídrica da bacia do rio Araranguá. Documento síntese, 1996. 
SEDIYAMA, G.C.; CHANCELLOR, W.J.; BURKHARDT, T.H.; GOSS, J.R. Simulação de parâmetros climáticos para a época de crescimento das plantas. Revista Ceres, Viçosa, v.25, n.141, p. 455-466, 1978.

SILVA, E. S.; ZAVISLAK, F. D.; DALLACORT, R.; CARVALHO, M. A. C.; ARAUJO, D. V. Distribuição de probabilidade de chuva no município de Sapezal, MT. Enciclopédia Biosfera, v.9, n.17, p1112-1122, 2013.

SILVA, J.C.;HEDWIEN, A.B; MARTINS, F.B.; TRENTIN, G.; GRIMM, E. Análise de distribuição de chuva para Santa Maria, RS. Revista Brasileira de Engenharia Agrícola e Ambiental, Campina Grande, v.11, n.1, p.67-72, 2007.

SILVA, D.D.; PEREIRA, S.B.; PRUSKI, F.F.; GOMES FILHO, R.R. Equações de intensidade-duração frequência da precipitação pluvial para o estado de Tocantins. Revista Engenharia na Agricultura, Viçosa, v.11, n.1, p.7-4, 2003.

SOARES, A.A. Evapotranspiração de referência e precipitação provável no Estado de Minas Gerais visando a elaboração de projetos de irrigação. Revista Engenharia Agrícola, Jaboticabal, v.18, n.4, p.14-18, 1999.

SOUZA, R.R.; ROSA, D.B.; NASCIMENTO, L.A.; LIMA, P.R.M. Estudo da variabilidade pluviométrica no extremo norte do Estado de Mato Grosso entre os anos de 1990 a 1996. Revista Geoambiente On-Line, Jataí, v.1, n.7, p.89$107,2006$.

THOM, H.C.S. A note on the gama distribution. Monthly Weather Review, Washington, v.86, p.117-122, 1958.

VIANELLO, R.L.; ALVES, A.R. Meteorologia Básica e Aplicações. Viçosa: UFV, 1991. 449p. 